\title{
Innovation changes and the traditional financial sector
} Agnieszka Wójcik-Czerniawska

PhD, Warsaw School of Economics (Warsaw School of Economics - SGH), College of Management and Finance, Poland.

Email: awojci5@sgh.waw.pl

\section{Keywords}

Innovation, Traditional Financial Sector,

Financial, Economic, Financial Instability.

\section{Article History}

Received on $8^{\text {th }}$ January 2021

Accepted on $23^{\text {rd }}$ January 2022

Published on $22^{\text {nd }}$ February 2022

\section{Cite this article}

Wójcik-Czerniawska, A. (2022). Innovation changes and the traditional financial sector. Humanities \& Social Sciences Reviews, 10(1), 24-33. https://doi.org/10.18510/hssr.2022.1014

Copyright @Author

Publishing License

This work is licensed under a Creative Commons Attribution-Share Alike 4.0 International License cc) (i) (2)

\begin{abstract}
Purpose of the study: The main objectives of this work are to analyze the innovation process in general and financial Innovation in particular, during which potential effects will appear on the financial structures of economic units and considering the recent financial events of the crisis of the subprime discuss whether financial Innovation is a source of growth or, on the contrary, is a source of financial instability.
\end{abstract}

Methodology: The financial crisis has cast a shadow over recent financial innovations, particularly those that call for risk elimination. This research used secondary methods for innovation changes and traditional financial sectors. The secondary research method will collect data through google, websites, books, and other sources.

Main findings: The main goal of financial technologies offered by entities in this sector is to improve the efficiency and availability of financial services, both from the customer and the perspective and a financial institution. The digital economy is considered a vertical-data-focused, and connected economy to the device, with a centralized architecture and heavy technology.

Application of the study: In debates about the regulation of financial markets, the functions and social use-value of financial Innovation come under scrutiny. In developing countries, the crucial question arises of to what extent financial innovation is essential to creating the financial infrastructure necessary for industrialization, instead of simply making wealth more liquid where blockchain technology and cryptocurrencies and crypto money become more active.

Originality/Novelty of the study: In this way, new products have been created, new forms of derivatives, products that transfer risk, and so on. It should be borne in mind, in any case, that the Schumpeterian vision of the innovation process in the present case that of financial Innovation is part of a regular course in terms of an economy that seeks growth. However, the financial crisis has cast a shadow over recent financial innovations, particularly those that call for risk elimination.

\section{INTRODUCTION}

\section{Background of study}

Digitalism is the more frequent manifestation of the post-digitization of the economy. The media, art, and other areas of socio-economic life, are terms and phrases in the economy of the 21 st century, which are inextricably linked with the development of information and communication technologies. Information and Communication Technologies, (ICT) of the 1990s. They are the aftermath of economic and social transformations, particularly implementing new business models, solutions, and communication channels in enterprises based on Internet technology solutions (An et al., 2018).

Among the most innovative industries globally is fintech, which supports financial services through technological solutions. A value of U.S. \$ 2 billion was invested in fintech companies worldwide in 2010, and more than \$ 15 billion was invested in 2015. Economic life is an endless field of possibilities. Each new financial service, a new type of economic activity leads to the dynamics of economic development. Some financial instruments arise and die out of lack of interest, and others. How bitcoins or various types of services make their way and function, reaching more and more followers.

The law and legal institutions are not so dynamic; therefore, the old rule "what is not forbidden is allowed" is often an additional driving force for introducing new institutions to the broadly understood area of the financial market. As financial markets, like others, are becoming more and more border-independent and becoming beyond national entities, regulation of various types of financial services must also take place across borders and be universal (Arthur, 2017).

There is no single international legislator yet to regulate the financial services market, but there are undoubted attempts to regulate at the European level. One of the most developing areas in law related to the financial market is tax law. You should not be surprised because when new forms of financial instruments are created, the tax authorities will follow 
them; the main goal is to look for the possibility of taxing instruments or services. The essence of the dispute indeed concerns the right to apply the exemption from tax on goods and services about providing information on the quotations of financial instruments provided in connection with the performance of other brokerage services exempt from VAT.

\section{Research Problem}

There are usually fees associated with business bank accounts at traditional banks. The fee is typically higher than banks online, and certain activities may incur additional costs. Depositing cash or checking can also be an additional charge. Modestly rising interest rates are among the positive factors impacting the financial sector. When rates rise, financial service providers can earn more on their cash and the credit they extend to customers (Jacolin et al., 2019).

\section{Research Question}

As a result, the question that needs to be answered is: What impact do digital banks have on traditional banks?

\section{Research Objectives}

As a result of the research question, this study aims to identify whether financial innovations like digital banks affect established financial intermediaries like banks. This goal is achieved through the following objectives:

- The purpose of this paper is to determine the gaps in the current situation by analyzing literature about financial Innovation and developing a theoretical basis for the concept.

- Analyze the performance indicators of traditional financial institutions that may be affected by the digital banking industry based on previous research.

- Assess digital bank impacts on traditional financial intermediaries, select the appropriate econometric model and collect relevant data to determine the model's potential limitations.

- Determine whether traditional financial intermediaries are challenged by digital banks based on the defined research methodology.

\section{LITERATURE REVIEW}

The following section of the thesis reviews academic literature relevant to financial Innovation and traditional financial intermediaries. In the literature review section, the reader will be familiarized with the characteristics of Innovation, its impact on economic performance, the types of financial innovations, some criticisms concerning these topics, and guidance in establishing a methodology for further investigation.

The responsibility for the services offered is also the element that should characterize financial instruments. This responsibility should be performed on several levels - but the most important should be the responsibility for the correctness of such a transaction, the accuracy of the data, and acting within the limits of justified economic risk. Not all financial instruments currently meet all these elements - and the availability of virtual currency, both in terms of its production and trading, does not make such actions credible.

\section{Financial Product Innovation}

There are many different explanations for "innovation" in the literature. Among the more notable definitions are Joseph Schumpeter, who is considered the inventor of this term, and E.M. Rogers, who is considered the father of innovation theory. In general, these two approaches are reflected in more recent definitions. Schumpeter viewed Innovation as being able to put new solutions into action. The author of these definitions defines Innovation as a perception of something new by an individual or group, the innovator. In addition to emphasizing its novelty, they also emphasize the contribution of two important facets during the implementation process, starting with the initial step of implementation, with the diffusion and infusion of Innovation into a wider system (infusion) (Bayona \& LLpez, 2018). It is not homogeneous how innovations are disseminated. The observation is made by A.H. Jawski, who emphasizes that introducing a new product into the marketplace sets a diffusion process in motion, including the diffusion of buyers' and suppliers' preferences. Using Schumpeter's terminology, diffusion of Innovation, which functions as the process of mass imitating innovations, is crucial, as innovators and their entrepreneurs cannot significantly influence the economy, even in breakthrough Innovation. Infused (absorbed) innovations succeed if they are skillfully transmitted to their target audiences. Based on the theory that Innovation doesn't happen through inventions, but through their application, which addresses the demand side of Innovation. Implementing a given innovation is more likely to succeed if it concerns many potential recipients (customers).

The importance of novelties or improvements in various categories of innovations deserves special attention. From this point of view, innovations can be distinguished: groundbreaking (radical, great, creative, fundamental); incremental (incremental, average), modifying the breakthrough invention; minor; and apparent, consisting of minor changes. Committee for Clearing and Settlement of Payments at the Bank for International Settlements in Basel, treating Innovation in retail payments as a new or significantly improved instrument, solution, or scheme that has achieved a significant market share or has such potential, basically equates radical and incremental innovations. Thus, it authorizes to omit specific terms (breakthrough, incremental) when discussing innovations. Various industries, including financial services, are being transformed by technological Innovation. In recent years, the financial sector has been transformed by 
financial technology, also known as "fintech." The emergence of digital technologies has created development opportunities for both the younger generation (fintech start-ups) and the more mature ones (e.g., traditional banks), allowing for more efficient operations, increased reach, and new business Finance and technology (Pradhan et al., 2018).

\section{Technology in Finance}

Using the abbreviation fintech (FinTech), that is, financial technology (fintech), is an industry-specific term to describe innovative financial services targeted to the financial industry. The concept of mobility has a great deal to do with how technology will revolutionize financial services in a way that has not been seen before: (BBVA).

The mobility of technology - Smartphones, tablets, and other mobile devices are considered ubiquitous. The Internet is no longer just accessed by personal computers. More and more people surf the web using their mobile devices. Mobile devices profoundly impact how financial services are provided and consumed.

The mobility of ideas - In this day and age, countless online platforms, websites, and networks allow people to connect. Space-time is compressed in these services: communications happen in real-time and information exchanges across traditional geographical boundaries. Sharing information, knowledge, and ideas across communities and geographies is possible.

The mobility of payments - Before now, it took several days and a lot of money to transfer to another country or currency. Thanks to online payment services, payment can be made online safely and at very low costs today. Besides enabling e-commerce, this has also helped inter-border financial transactions, such as lending and investing, become faster and more efficient (Wang, 2021).

In the financial sector, the following technological trends have the most significant impact: (BBVA)

\section{Mobile and digital payments}

Mobile applications and NFC technologies are increasingly being used in payment services. A cash register's clumsiness is history. A tablet or smartphone paired with a small backpack less than the size of a matchbox can be used to accept payments today. We are just at the beginning of evolution. In the future, payments in restaurants and stores will not be handled in person but over the Internet, utilizing customers' smart devices. In the future, we could see close to seamless payments (contactless), where the customer is automatically identified, merchandise is checked, and the customer is charged upon leaving the store (Singh et al., 2021).

\section{Authentication and biometrics}

Many financial services and many financial transactions require authentication of one's identity. Technological advancements are likely to lead to more efficient and secure identity authentication solutions. Within a few years, we won't have to worry about remembering complex passwords or being breached by hackers. Authentication systems are being explored using biometrics such as fingerprints, iris scans, facial and vocal recognition, palm scans, and even heartbeats. Different parts of the world have implemented biometric ATMs, from the U.K. to Japan, China to Brazil, and Poland. Banks has launched the Touch ID fingerprint authentication feature of the iPhone in Singapore. Voice biometrics is also being looked into for use in banks and call centers. The use of token-based authentication presents an alternative solution to users concerned about privacy or physical impairments: embedded tokens, such as those included in wearable technology, can ensure greater security. These can be used with biometrics to provide multiple authentications (Ann Shaji, 2016).

\section{Blockchains and distributed ledgers (distributed ledgers)}

Several people have expressed interest in digital currencies, such as Bitcoins. With bitcoins, payments can be made much faster, cheaper, and more secure than traditional wire transfers, as well as more secure, as bitcoin advocates claim. Digital currencies remain to be seen whether they have the potential to take off, but many banks are keeping a close eye on it. One day, if they do catch on with consumers and central banks alike, it's not impossible that they will issue their digital currencies. However, in terms of the economy generally, bitcoins' biggest impact will be the blockchain technology - known as distributed ledger technology. This decentralized property registry is the most significant characteristic of the blockchain. Once input within the system, the process encrypts documents and assets into an irrevocable digital record. Another party in the system can verify the digital record without a centralized authority. Distributed ledgers may offer the following benefits: increased performance and efficiency, lower operating costs, and better resistance to system failure (Serena et al., 2021).

The financial sector has many potential uses for distributed ledger technology (distributed ledgers): Ripple, an American company, has developed a real-time gross settlement system based on distributed ledger technology to facilitate remittances and foreign exchange. Regulators could use the same solution to monitor risk and online transactions to detect terrorist financing or money laundering. Legal professionals, too, will likely be interested in these systems since they can be used in any field that relies on third parties to verify contracts and transactions. A distributed ledger system is being developed for property title registration in Honduras. In addition to registering intellectual property rights, managing supply chains, and conducting electronic elections, others spoke of potential applications. 


\section{Use of Fintech in innovation Process}

In its proposal, the Basel Committee defines fintech as technologies that provide a new business model, applications, service, or product that have significant implications for financial institutions. Financial technologies offered by firms in this sector serve both the customer and the institution by improving efficiency and availability of financial services.

Among the many entities that make up the fintech sector are:

Mobile payment apps are available from various technology companies (including Apple Pay and Google Pay) to enhance their ability to process payments. Several neo-banks compete with large fintech companies, such as Zynga from China, Revoluta from the U.K., or Nonbank from Brazil (Chuen \& Ling, 2020).

The rapid development of the latter is extremely interesting. It was established in the United Kingdom in 2015, initially as a currency exchange platform, and in 2018 it received a license from the Bank of Lithuania (thanks to which its deposits are guaranteed in Lithuania up to EUR 100,000), which allows users to include transfer and payments in various currencies (also in cryptocurrencies) without fees for using prepaid cards and mobile applications. During three years of operation, it gained 3 million users (with the population of Lithuania 2.8 million in 2017).

Trust, i.e., the expectation of the credibility of a word, promise, oral or written promise of another individual or group, is more important in the case of the fintech sector as it operates mainly in the virtual world. Hence, the trust in fintech entities is significantly influenced by consumers' previous experiences from working with them. Positive experiences translate into slightly higher customer confidence in entities fintech (56\%) than traditional entities (53\%) 19 . This is a significant element of risk for banks, and it is even more important that in 2016 over $26 \%$ of buyers of banking products and services cooperated with the fintech sector, but only $2.9 \%$ of respondents cooperated only with it.

The principle of fintech companies is to introduce technological innovations from the outside in rather than from the inside out. This means that innovative changes are primarily subordinated to removing negative ones and creating positive customer experiences that arise while using the company's services. Innovations are often the result of cocreating them with customers, as well as with other stakeholders. The concept of co-creation consists of introducing all interested groups of stakeholders to cooperate in creating new products, not only employees but also customers, suppliers, etc. use from its offer (Leong, 2018).

\section{METHODOLOGY}

The methodology chapter discusses or proposes a clear structure that the researcher will adopt for conducting this research. It has been said that the methodology section should include a critical evaluation of the subject area's methodologies and principles. The chapter aims to discuss the philosophical foundations related to the research methodology. The researcher aims to discuss the research plan, strategy, data collection, ethical considerations, and study limitations.

\section{Research Method}

A secondary research method has been applied to explore the broad aspects of traditional financial innovation strategies. Financial Innovation is not a new phenomenon in the economic landscape. It has been developing for a long time. The second type of research is already being gathered, collected, organized, and published. You can find government reports, trade associations, and other studies on your industry. For mixed methods research to have a high level of scientific rigour, the design of mixed-method research questions requires combining qualitative and quantitative aspects, emphasizing the rationale, and selecting appropriate mixed methods. A correlation matrix is generated using the transformed and adjusted data to test for correlation. The OLS analysis requires testing for correlation as high correlations between exogenous variables can cause collinearity (Berlinger, 2017).

If the regression variables are highly collinear or multi-collinear, it might affect their significance. A correlation between these two factors can be expected since bank loans commonly make up substantial assets. Although both variables are not included in a single regression in the OLS analysis, the relationship between loan growth and asset growth shouldn't be a concern. We construct a correlation matrix to test the correlation between the exogenous variables, and if the correlation is higher than 0.8 , we calculate the Verify and evaluate them to see if significant collinearity exists.

\section{Performance Measures}

Previous research on the performance of digital banks examined how they compare to traditional banks, as is described in the literature review. The main purpose of this thesis is to examine whether digital banks affect traditional banks' performance, if there is a difference, and determine whether this difference is positive or negative. In both traditional and digital banks, the previous literature is viewed as a benchmark in defining measures for evaluating performance.

According to common practice, performance ratios are generally separated into liquidity (risk), solvency (liabilities), and activity; however, since banks are not just businesses but also have different financial reporting requirements than corporations, ratios of performance also need to differ. The ECB defines bank performance as "reliability and sustainability of earnings," along with "adequate liquidity, risk-taking, and leverage (Prentice, 2016). 


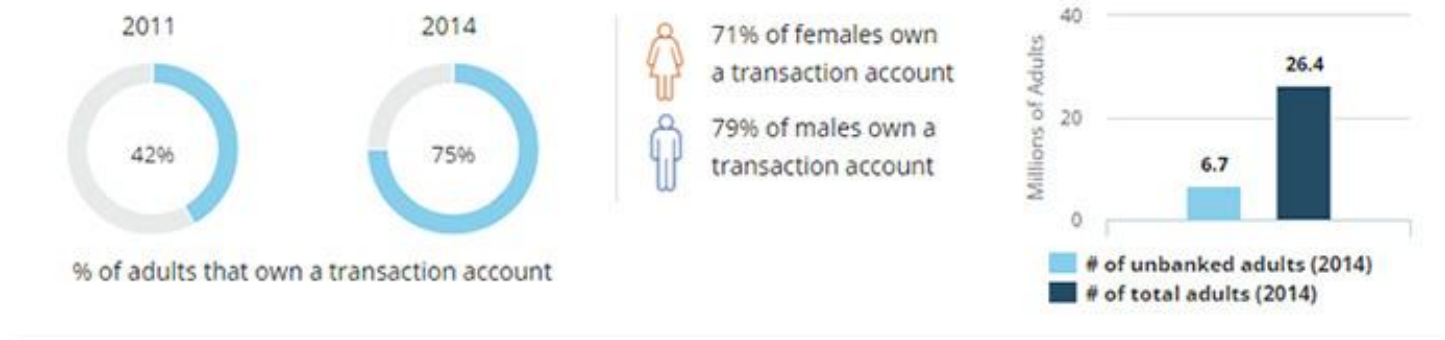

Country opportunities:

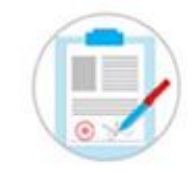

7.1 Million

Adults

By drafting and

implementing a National

Financial Inclusion

Strategy (NFIS)

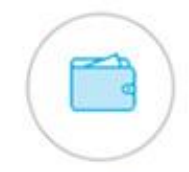

0.2 Million

Adults

By digitizing government

to person (G2P) cash

transfers

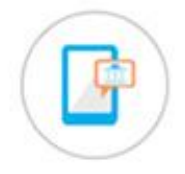

5.5 Million

Adults
By opening up the market and legal/regulatory environment

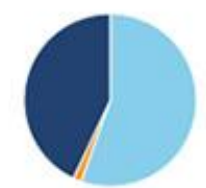

\% drafting/implementing NFIS

ID digitizing G2P cash transfers

\% opening up market and legal/regulatory environment

Figure 1: Bank Performance

Source: $\underline{\text { Prentice, } 2016}$

There is little variation in the methods used to measure and classify performance ratios; however, the main ratios are consistent across all research. They compared 17 financial ratios, including return on equity and return on assets, as well as loan-to-deposit ratios even though the performance ratios were limited to eight in the study for European banks, which consisted of profit, leverage, business activity, and capitalization.

\section{Digital Bank Measures}

The United States' banks at the time of the research were making almost half of their operating profit from non-interest income rather than just interest income as was previously thought. Non-interest income represents one of the principal performance drivers of a bank due to such growth of non-interest income. Among the most significant non-interest income sources is the payment services sector. Customer activity generates revenue for payment services; thus, their income is largely determined by the number of banking customers. HOWEVER, the U.S. government does not require banks to report data on numbers of users or the value of transactions. In contrast, the growth rate of deposits can also be explained by the increasing number of users, which is one of the main reasons deposits increased. A rise in deposits at digital banks will negatively impact traditional banks' users, which will affect revenue and profits (DOĞAN \& ÖVENCC, 2021).

\section{Research Instrument}

In ordinary least squares (OLS), analysis is a common econometric technique used to define relationships among variables. OLS analysis can be useful in some instances, but not when it predicts causal relationships as it does not automatically prove causality (Studenmund, 2017). The impact of digital banks on traditional banks cannot be established empirically. Therefore, it must first be proven in empirical research. It is possible to test for statistical causality using the Granger causality method even though there is no empirical method for proving actual or "theoretical" causality. Consequently, this thesis has chosen it as the principal testing method with a secondary analysis based on OLS. OLS analysis is performed on the variables that proved to have a causal relationship (Krylov, 2016).

\section{Data Collection}

Though little research has been conducted about how traditional financial intermediaries will be affected by digital banking, there has been significant research conducted in the years preceding the financial crisis. After the financial crisis, post-crisis literature tends to be descriptive, and little research has been conducted on how digital banks will impact traditional banks. Additionally, how digital banks affect traditional financial institutions does not differentiate between digital banking and FinTech. Although there has been less research done on the European market than the U.S. market, this thesis examines both traditional and digital commercial banks operating in the U.S. Many digital banks in Europe are still in the start-up phase, whereas digital banks in the United States are more established. Due to this, the U.S. market has more extensive statistics, and the survival of start-up banks is less uncertain (Jeet \& Aspal, 2020).

These are the conditions that traditional banks must meet to be measured in this research: 
As a result, only active and fully operational banks are considered for the research. Banks must make money from their basic banking services to qualify as commercial banks, not from investment banking. To qualify as a bank, a financial intermediary must derive its income from basic banking services and not from any other financial type of service. Traditional channels such as branches are the primary channel through which the bank distributes its services and products. For a bank to be classified as a traditional bank, it is expected to generate most of its financial gains from traditional distribution channels instead of digital ones.

\section{RESULTS}

This section of the thesis discusses the findings of the empirical research conducted. Technology is changing the financial services industry as well as the entire economy. The financial technology sector, known as "fintech," has increasingly transformed the world's financial sector. Fintech start-ups and traditional banks benefit from technological changes as they reduce costs, expand their reach, introduce new business models, and, most importantly, enhance positive customer experiences.

\section{Innovation and Economic Performance}

A crucial aspect of the economy is Innovation, regardless of what form it takes. Changes in static factors have been seen as reasons for economic growth for a long time. However, most authors agree that innovations are the driving force behind economic development in the long run. Assuming that the entrepreneur creates the Innovation, economic growth is boosted. Schumpeter introduced this theory. First, Solow developed a model that justified the importance of Innovation to economic growth. The only force that can spur long-term development, according to Solow, is Innovation. Despite Solow's focus on financial Innovation, economic and technological advancement would be slower without financial Innovation. No matter how crucial the allocation of static resources may be in the short-term, Innovation drives the economy (Popadić, 2016).

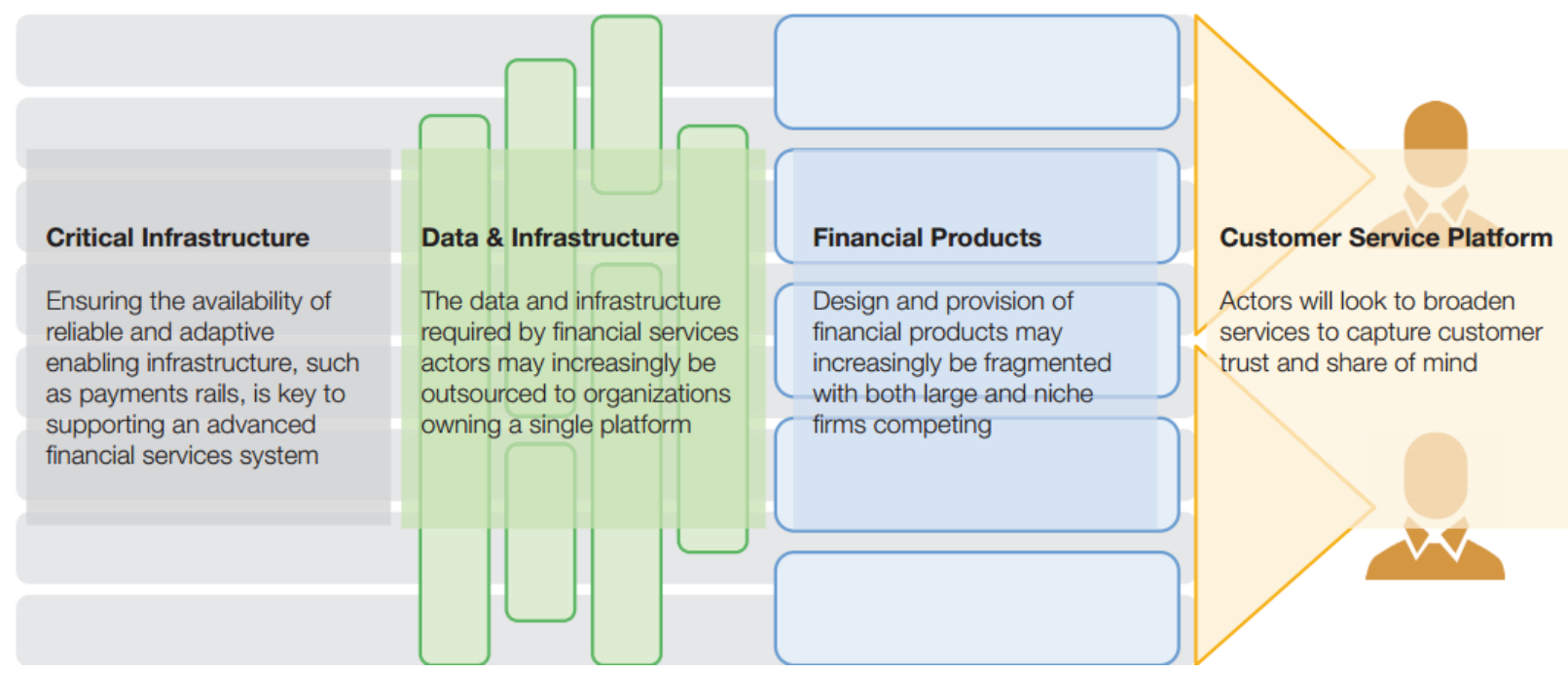

Figure 2: Financial Innovation

Source: $\underline{\text { Popadić, } 2016}$

In addition to justifying the importance of Innovation to economic growth, evolutionary economics also assists in justifying its importance. When firms' rate of return falls below a certain value, they look for innovative ways or processes that other firms are already using that are likely to increase profits. Numerous authors to this day have examined the relationship between Innovation and economic performance, and it can be authoritatively stated that Innovation and other industries are linked.

\section{Innovation and other sectors}

In Considering how non-financial innovation shapes existing, traditional companies, we can discuss the impact of financial Innovation on traditional financial intermediaries. Firms that are more focused on their current customers and competitors than future customers and competitors are more likely to suffer losses or even cease to exist due to radical Innovation. Thus, this theory can also be assumed to apply to traditional financial intermediaries. If Innovation is used in conjunction with traditional services, for example, it complements or replaces them depending on how they are used, more effectively meeting consumer needs. According to consumer theory and the findings from research, traditional financial intermediaries are also being impacted by financial Innovation. In the absence of integrating the Innovation with traditional financial intermediaries, it may pose a threat to their existence, but on the other hand, if it is combined with them, it will prove complementary (Kerstens et al., 2018).

\section{Innovation and Financial sectors}

As the economy's core, the financial sector plays a critical role in economic growth. Financial depth enables mobility and pooling savings, stimulating capital accumulation and enhancing allocation. By reducing transaction costs, 
encouraging specialization, and reducing liquidity risks, the financial markets can help the economy grow more productively. However, a growing economy promotes the development of the financial sector, according to demandfollowing models. The hypothesis suggests that when business growth occurs, market participants demand better and more sophisticated financial services, which leads to the improvement of the financial sector. However, growth in one sector may cause growth in the other and vice versa (Cong, 2019).

Historically, Innovation has been a major research topic in academia, and it still raises many questions, one of which is what impact does it have on economic development? In recent years, a lot of attention has been paid to the financial sector and its relationship with overall economic performance. Economic growth and the financial sector, as we discussed before, are thought to be causally linked, whether it is reciprocal or one-way. The importance of financial Innovation is, therefore, only natural. But despite the overwhelming academic literature on both the financial sector and Innovation and the correlations between them and economic Introducing New Processes.

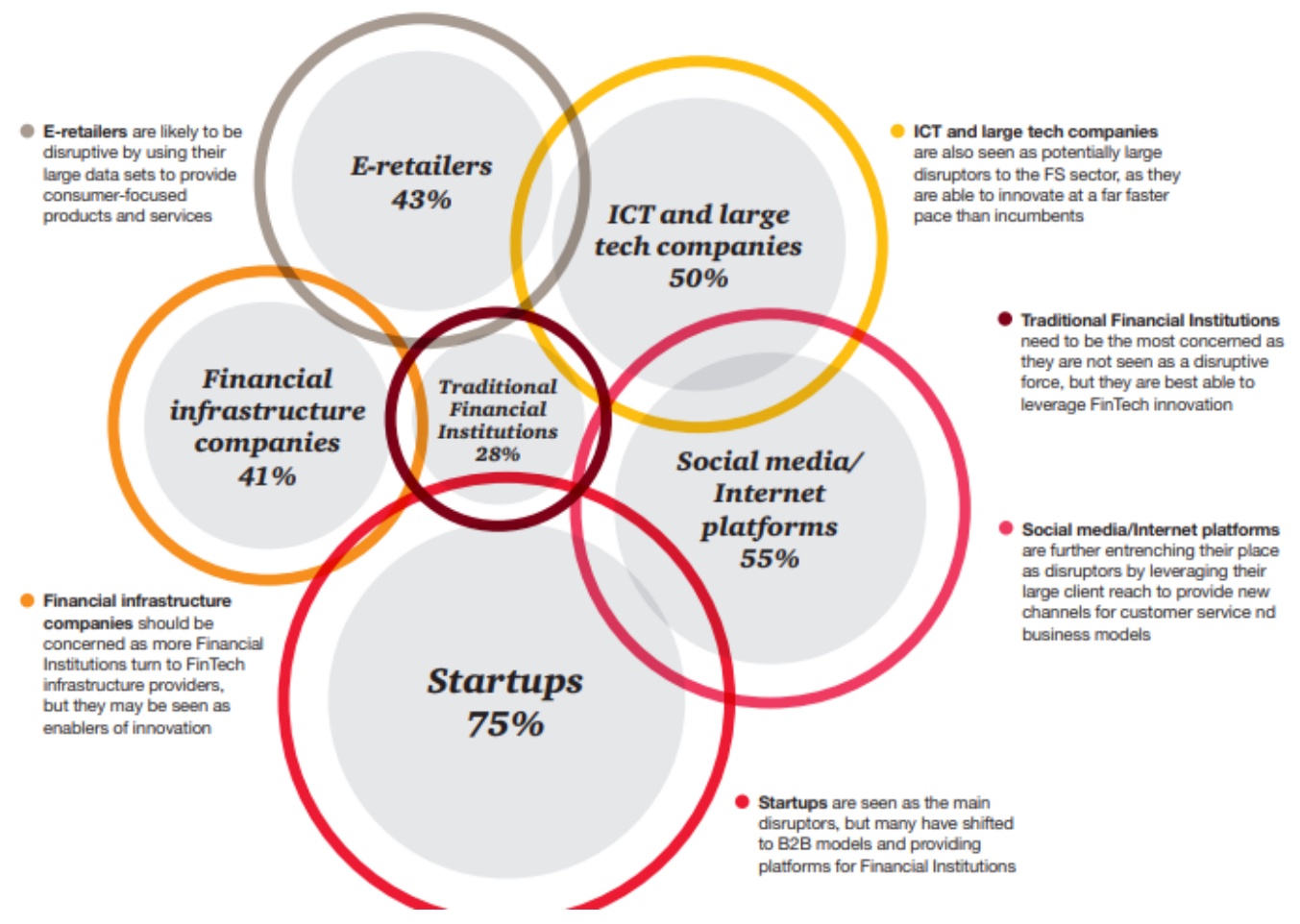

Figure 3: Correlation between Financial sector and Innovation

Source: Cong, 2019

\section{New Process}

An innovative process is established within the company that has never been implemented before. If a new process is new to the entire financial sector, it is considered an innovation in financial services. Automated clearinghouses, risk management, asset securitization, and internet banking are some of the main research topics in the new process area. The following sections discuss automated clearinghouses and internet banking.

Automated clearinghouse. Among other automatic payments, payroll, taxes, and consumer bills are handled by the Automated Clearing House $(\mathrm{ACH})$ through electronic transfers of funds. In the 70s, ACHs were invented, but they gained widespread acceptance in the 80s. Payments via automated clearinghouses in the U.S. totaled 24 billion transactions in 2015 with a value of $\$ 41,6$ trillion.

With their article on international automated clearinghouse growth, automated clearinghouses have not lost their market share. The payment volume is predicted to double to more than 420 billion transactions by 2010. Global Payments report, however, indicates that 433bn transactions were made in 2014-2015. As the authors state, an increase in non-cash transactions also contributes to the digitalization of finance, as cash transactions are declining and cash transactions are growing (

Internet banking. Oxford Dictionaries defines online banking as "the process of conducting banking transactions through the Internet using electronic means." A major innovation for the banking industry is internet banking. The majority of research on internet banking focuses on the characteristics that encourage implementation of the benefits that result from implementation. Several factors influence whether or not internet banking is implemented. These include the bank's size, age, and location. It has been found that banks located in large cities younger and larger banks implement internet banking more quickly. In the context of innovation impact on traditional bank performance, this would mean that internet banking increases bank performance measures, including deposits and revenues (E Jarrett, 2015). 
Despite being more widely adopted and growing, there is no recent research on how internet banking affects traditional banks. Internet banking might move from being a complementary to a main form of banking as the financial world moves towards a more digital landscape, resulting in a gap in the literature.

\section{DISCUSSION}

In the thesis part, a summary and review of the results and discussions of their practical implications will be presented. It will also provide suggestions for research in the area and examine the implications of limitations discussed in the research methodology section.

The importance of novelties or improvements in various categories of innovations deserves special attention. From this point of view, innovations can be distinguished: groundbreaking (radical, great, creative, fundamental); incremental (incremental, average), modifying the breakthrough invention; minor; and apparent, consisting of minor changes. Committee for Clearing and Settlement of Payments at the Bank for International Settlements in Basel, treating Innovation in retail payments as a new or significantly improved instrument, solution, or scheme that has achieved a significant market share or has such potential, basically equates radical and incremental innovations. Thus, it authorizes to omit specific terms (breakthrough, incremental) when discussing innovations.

It is important to underscore that financial Innovation is about creating a novelty and reducing costs, reducing the risk, or providing better products, services, processes, and instruments that are more in line with the needs of participants in the financial markets. Innovation is not disseminated homogeneously. This is pointed out by emphasizing that the appearance of a new product on the market starts the process of diffusion of (product) innovation that can be understood in two ways, namely as "diffusion on the buyers' side and as diffusion on the suppliers' side.

In Schumpeter's terminology, innovation diffusion refers to imitators of innovative solutions on the supply side of innovation implementation. Breakthrough Innovation cannot change economic conditions significantly without the supply of an inventor's entrepreneur. Innovative products, services, etc., are popularized by placing them in the right hands based on the belief that innovations don't make the world go round, but the application of the inventions that make them succeed. Implementing a given innovation has a greater chance of success when it concerns a larger group of potential recipients (customers) (Messori, 2002).

The growth of loans in digital banks and deposits can be used as a proxy for the growth of digital bank customers. Therefore, this data illustrates how quickly new customers can be attracted to digital banks. As a result, loan growth would diminish the amount of interest income that a traditional bank earns. However, ROA, ROE, and NIM do not appear to be causally related, as one would expect. In this case, testing combined ratios instead of sole financial factors might result.

According to what we discussed earlier, digital bank loans are likely to decrease both the traditional bank loan portfolio and all assets (through loans). Because of this, the decline in interest income might offset the impact of the decrease in assets, so it is impossible to prove a causal relationship between the two. This reasoning is also applicable to the NIM ratio when loans decline, as the reduction in interest revenue will not be large enough to make up for the reduction in the overall ratio. It should be noted that these assumptions are only estimates. A more thorough study would provide more definitive answers. Further research might examine how different variables affect financial ratios rather than noncombined measures, as was done with deposit growth and asset growth ("Changes in the financial performance of $\underline{\text { traditional intermediaries for financial innovation," 2019). }}$.

When evaluating this research in light of previous literature, it is important to note that no research has been done on the impact of digital banks on traditional banks. Thus, the review is limited. However, despite its limitations, the present paper can serve as a foundation for further research due to the lack of previous literature in this area.

\section{CONCLUSION}

Digital technology, which a few years ago was a distinguishing feature in the economy and was the source of the competitive advantage of entities operating in it, nowadays contributes to changing the relationship between business and society. In the post-digital economy, products and services, the environment, and conditions of functioning are designed based on the anticipated needs of individual consumers and their emotional states in every aspect of their lives. As long as the digital economy is considered a vertical, data-focused and connected economy to the device, with a centralized architecture and the so-called heavy technology, the post-digital economy is a personalized economy based on intelligent solutions and autonomy, distributed architecture and design thinking. The main distinguishing features of post-digital in the economy are new relationships between the business and the consumer and the growing role of neoconsumers and professional prosumers, who are among the most important entities in the post-digital economy.

Post-digitization in the economy is one of the main determinants of the fourth industrial revolution, which is reflected, among other things, in the transformation of entities and digital phenomena into a new era. Post-digital is blurring the boundaries between offline and online, emphasizing connectivity and networking and 'digital on-demand services. Postdigital breaks with terms such as digital marketing for modern marketing, online banking for modern banking, ecommerce for modern commerce. In a post-digital economy, adopting digital tools and methods are no longer a competitive advantage but a challenge for enterprises in creating new business models based on the basic capabilities of the trend called SMAC (social, mobile, analytics and cloud), i.e. social media, mobility, analytics and cloud computing. 
On the one hand, the issue of post-digitization in the economy takes the form of in-state development, and on the other, it concerns issues that already have their history and tradition. The story of the post-digital economy is related to, among other things, combining what has already been with what is yet to be shaped. Implementation Restrictions research and formulation of conclusions regarding post-digital economy are mainly objective and external determinants. It is currently difficult to predict what new and post-digital trends will appear in the economy of the 21 st century. Undoubtedly, many of them will be affected by the COVID-19 epidemic.

\section{LIMITATIONS}

A section on the potential limitations of the chosen research methodology and data follows.

- Traditional banks are mainly brick-and-clicks, which means that they also use the Internet to distribute their products, only not exclusively. Studies comparing traditional and digital banks may therefore be biased. Nevertheless, most banks in the United States are brick-and-mortar establishments; thus, this bias is inevitable.

- One limitation of this study might be the performance measures selected for traditional banks.

- In general, performance measures give us a glimpse of the past, but they do not necessarily indicate what the future will bring.

- It can be hard to identify which particular financial measures are affected by the digital bank factors, as performance measures are a combination of different financial measures of the bank.

- Last but not least, financial measures in traditional banks can be offset by changes in digital bank factors. Thus, this impact may be invisible.

\section{ETHICAL STANDARDS}

According to conventional morality, ethics deals with how human behavior should be acceptable or 'right' and 'wrong'. Truthfulness, integrity, honesty, respect for others, and fairness are considered general ethical norms. The principles apply to business and financial decisions as well. General ethics entails financial ethics as well.

People interact in social situations, where ethics play a critical role in maintaining stability and harmony. Social behavior components that contribute to social stability are recognizing others' needs and aspirations, fairness, and cooperative efforts. Our evolution has resulted in developing both instincts to care for ourselves and an awareness of how to care for others.

However, there may be times when the need to look after ourselves conflicts with looking after others. It is in these cases that ethics can be of assistance. An ethical perspective reconciles our material needs and our conscience in the face of conflict between selfishness and selflessness.

A subject of study for a long time, ethics in finance has gained in popularity in recent years. In addition to honesty, transparency, fairness, and sustainability, it endeavors to make the decisions of an increasingly large and diverse group of banking consumers more ethical. In general consumption and financial products (albeit to a lesser degree), the Goldman Rule to pursue profitable opportunities is disappearing.

\section{REFERENCES}

1. An, H. R., Kim, S. Y., \& Kim, C. K. (2018). Connectivity in global stock markets during the financial crisis. Crisis and Emergency Management: Theory and Praxis, 14(1), $193-211$. https://doi.org/10.14251/crisisonomy.2018.14.1.193

2. Ann Shaji, N. (2016). A survey on biometrics authentication for online transactions. International Journal of Engineering and Computer Science. https://doi.org/10.18535/ijecs/v5i11.93

3. Arthur, K. N. A. (2017). Financial Innovation and its governance: Cases of two major innovations in the financial sector. Financial Innovation, 3(1). https://doi.org/10.1186/s40854-017-0060-2

4. Bayona, A., \& LLpez, ngel L. (2018). Silent financial interests and product innovation. SSRN Electronic Journal. https://doi.org/10.2139/ssrn.3199740

5. Berlinger, E. (2017). Implicit rating: A potential new method to alert crisis on the interbank lending market. Finance Research Letters, 21, 277-283. https://doi.org/10.1016/j.frl.2016.11.010

6. Changes in the financial performance of traditional intermediaries for financial Innovation. (2019). VOLUME-8 ISSUE-10, AUGUST 2019, REGULAR ISSUE, 8(10), 3723-3728. https://doi.org/10.35940/ijitee.j1052.0881019

7. Chuen, D. L. K., \& Ling, C. L. S. (2020). Blockchain use cases for inclusive fintech: Scalability, privacy, and trust distribution. The Journal of FinTech, 2050003. https://doi.org/10.1142/s2705109920500030

8. Cong, P. T. (2019). Creative industries, investment trends and their impact on the economy and financial sectors: A study from Vietnam. International Journal of Innovation, Creativity and Change, 31-49. https://doi.org/10.53333/ijicc2013/07504

9. DOĞAN, M., \& ÖVENÇ, G. (2021). Central bank digital currencies under blockchain technology: Discussion of digital bank runs and design principles. European Journal of Science and Technology. https://doi.org/10.31590/ejosat.916233 
10. E Jarrett, J. (2015). On internet banking. The Journal of Internet Banking and Commerce, 20(2). https://doi.org/10.4172/1204-5357.1000101

11. Foianini, I., \& Dragani, J. (2015). Building a Career in Reserves Estimation. The Way Ahead, 11(02), 22-24. https://doi.org/10.2118/0215-022-twa

12. Hoag, C. (2016). Clearinghouse loan certificates as interbank loans in the united states, 1860-1913. Financial History Review, 23(3), 303-324. https://doi.org/10.1017/s0968565016000196

13. Jacolin, L., Massil Joseph, K., \& Noah, A. (2019). Informal sector and mobile financial services in developing countries: Does financial Innovation matter? SSRN Electronic Journal. https://doi.org/10.2139/ssrn.3396046

14. Jeet, V., \& Aspal, P. K. (2020). The determinant of financial performance of Indian public sector banks- A panel data approach. International Journal of Financial Research,11(5), 285. https://doi.org/10.5430/ijfr.v11n5p285

15. Kerstens, N., Dolmans, S., \& Reymen, I. (2018). Initiating cross-sectoral Innovation - bringing space technology to other sectors. Academy of Management Proceedings, 2018(1), 18182. https://doi.org/ 10.5465/ambpp.2018.18182abstract

16. Krylov, S. (2016). Applied strategic financial analysis as an innovative instrument to strategic research aspects of the organization financial activity. SSRN Electronic Journal. https://doi.org/10.2139/ssrn.2834252

17. Leong, K. (2018). FinTech (financial technology): What is it and how to use technologies to create business value in a fintech way? International Journal of Innovation, Management and Technology, 9(2), 74-78. https://doi.org/10.18178/ijimt.2018.9.2.791

18. Messori, M. (2002). Credit and money in Schumpeter's theory. SSRN Electronic Journal. https://doi.org/10.2139/ssrn.320883

19. Popadić, M. (2016). Exploratory innovation, exploitative innovation and innovation performance: the moderating role of alliance partner diversity. Economic and business review, 18(3), 293-318. https://doi.org/10.15458/85451.26

20. Pradhan, R. P., Arvin, M. B., Nair, M., Bennett, S. E., \& Hall, J. H. (2018). The dynamics between energy consumption patterns, financial sector development and economic growth in financial action task force (FATF) countries. Energy, 159, 42-53. https://doi.org/10.1016/j.energy.2018.06.094

21. Prentice, C. R. (2016). Why so many measures of nonprofit financial performance? Analyzing and improving the use of financial measures in nonprofit research. Nonprofit and Voluntary Sector Quarterly, 45(4), 715-740. https://doi.org/10.1177/0899764015595722

22. Serena, L., D’Angelo, G., \& Ferretti, S. (2021). Security analysis of distributed ledgers and blockchains through agent-based simulation. Simulation Modelling Practice and Theory, 102413. https://doi.org/10.1016 /j.simpat.2021.102413

23. Singh, J., Kumar, A., \& Raghuvanshi, K. K. (2021). Evaluation of mobile-based digital payments and challenges. International Journal of Digital Literacy and Digital Competence, 12(1), 15-29. https://doi.org/10.4018/ijdldc.2021010102

24. Wang, Z. (2021). Research on risk control strategies of consumer finance based on big data technology. Finance and Market, 6(1), 40. https://doi.org/10.18686/fm.v6i1.3173 